\title{
Monitoring as an instrument of Sustainable Urban Development
}

\author{
Tatyana Kharlamova $^{1^{*}}$ \\ ${ }^{1}$ Peter the Great St.Petersburg Polytechnic University, Polytechnicheskaya, 29, St. Petersburg, \\ 195251, Russia
}

\begin{abstract}
The article considers the necessity of active implementation of monitoring, as a managerial instrument, into the process of urban development. It will provide the creation an effective informational support of sustainable development of the modern cities. Today the central part among them belongs to megacities. The presented research focuses on megacities from the positions of the most significant trends of globalization. On this basis the author makes a number of proposals in a framework of creation the monitoring system for effective informational support of sustainable urban development. The operation of this system corresponds to the basic foundations of the Information society and the modern conditions of postindustrial development.
\end{abstract}

\section{Introduction}

The new realities of the global and national economies require the transformation of the system of national and subnational regulation. We are currently witnessing a search for a new design of economic growth. The complex, and even dramatic, processes taking place now, in the period of new global challenges and shocks, are having an impact on the entire world economy [1].

In this context we are talking about the increasing role of regulation the processes of sustainable urban development, as an important subsystem of the economic development. There are megacities as subjects of globalization in the center of this subsystem. It is necessary to point out that $60 \%$ of the world GDP falls only on 600 megacities (so-called, City 600). 380 megacities are located in developed countries and produce $50 \%$ of world GDP, while 220 megacities of developing countries - only $10 \%$ [2].

In 2009, PriceWaterHouseCoopers conducted the research of the role of megacities in the global economy. In the framework of this research New York, Tokyo, Singapore, Shanghai and other cities were considered. PriceWaterHouse experts concluded that the role of megacities in the future global economy will increase. They will concentrate the most active, creative part of the population and also - world industry, finances, innovations, telecommunications. Therefore the future of the world is for such megacities. The informal club of such cities-economic leaders was created at the end of 2009 in Milan. In the future it may become a certain analogue of the G20 [3].

\footnotetext{
* Corresponding author: Kharlamova_t@list.ru
} 
The process of regulation of sustainable urban development has a great importance not only for the national but also the global economy. Its theoretical basis in a number of provisions coincides with the theories of regulation of economy. This is explained by the thesis that megacities represent an economically developed part of the national and world economy [4].

In these conditions, the main task of regulation is associated with determining the forms of cooperation of numerous economic entities and ensuring their interests at all levels of the national and world economy. These issues are relevant for all urban agglomerations, different in scale [5]. The effectiveness of the regulating process of sustainable urban development involves the reliable information support. It forms such requirements for informational resources as relevance, accuracy, veracity and timeliness. The satisfaction of these requirements is connected with use a managerial tool of monitoring in the process of sustainable urban development.

\section{Materials and Methods}

The functioning of an effective regulatory system is able to provide not only faster and sustainable development, but also the transfer to the innovative type of economic growth. In the modern conditions it is especially important for the Russian Federation [6].

It should be understood that at different stages of the life cycle of the megacity the goals of development could be transformed, as well as the tasks, managerial tools and evaluation criteria. In addition, we can see a great influence of the external and internal environment of the megacity including the experience and knowledge of people and the level of their economic and political thinking [7]. This indicates the need of implementation a monitoring system in the process of strategic management of the megacity.

Such actions should be based on the accurate analysis of all aspects of the development of megacity by means of monitoring. Today, it is proposed to implement monitoring in the following areas of sustainable urban development:

- production monitoring for assessing the level of effectiveness of the internal environment of the economic activities of the companies located on the territory of the megacity;

- monitoring of information obtained from the analysis of the external environment, for inclusion it in the strategic and operational plans of the megacity;

- $\quad$ investment monitoring for assessing the effectiveness of investment projects and the attractiveness the megacity for investors;

- financial monitoring for assessing the effectiveness of sources of financing the economic development of the megacity;

- innovative monitoring for estimation the possibility of the practical implementation of innovations by the enterprises located in the megacity.

These five interrelated areas of monitoring should be considered as a tool for determining the starting point in moving towards the sustainable and long-term economic development and economic growth of an innovative type. In addition, the issues related to the environment and efficient use of natural resources should be analyzed [8,9].

At the same time, the construction of an effective monitoring system involves the availability of methodological foundations arising from the tasks and the place of monitoring in the system of sustainable development of the megacity. It requires an establishing a certain order of relations between all functional subsystems of the economic system of the megacity. Such functional actions as attracting investors, stimulating scientific and innovative processes, training employees, etc., need a common approach to informational support in the framework of the megacity. This is particularly important in the conditions of forming the Knowledge economy and the Digital economy [10, 11]. 
The analysis and testing of all elements of the economic system of the megacity is carried out in the process of monitoring for identification the causes of real and possible shortcomings. It allows the Administration of the megacity to aggregate information for the working out, adoption and implementation different managerial decisions [12].

In this context monitoring displays the direct, indirect and reversed links between all elements of the economic system and creates the foundation for implementation of the main important managerial functions: planning, organization, motivation, accounting and control. In turn, monitoring affects the economic system as a means of identifying and eliminating the causes of problems [13].

In this regard, the methods of monitoring have not only theoretical, but also practical interest. In this regard a new method of monitoring could be proposed. The implementation of the proposed method is based on the following actions:

1. Development an effective model for the development of monitoring;

2. Analysis of negative and positive factors influencing on the formation of the monitoring system;

3. Formation an effective organizational structure of monitoring system;

4. Collection and processing the results of monitoring;

5. Generalization the obtained results of monitoring and identifying trends in the studied processes;

6. Preparation an appropriate documentation for the organization the system of monitoring;

7. Determining the composition of participants of the system of monitoring and working out the requirements to the level of their qualification.

These actions determine the configuration of the monitoring system. Its functioning depends on a number of specific processes combined in five stages.

The 1st stage. It's devoted to justification and preparation of managerial decisions connected with implementation of monitoring system [14].

The analysis of domestic and foreign practice has shown that the favorable moment to start this system is the appearance of signals about the possible risks and problems.

The basic conditions for the creation of the system of monitoring are:

- $\quad$ poor consistency of different tasks;

- $\quad$ outdated methods of planning;

- $\quad$ decrease in economic indicators to a level close to critical;

- lack of accounting and analysis techniques, resulting in a lack of analytical information;

- $\quad$ emergence of new tasks and correction the goals in a changing situation;

- poor coordination among different divisions/committees of the Administration of the megacity;

- duplication of certain functions or their absence;

- emergence of conflict situations in the process of functioning of communicative system etc.

The 2nd stage. This is a stage of modernization of the accounting system of the companies. This system plays the central role in informational support of internal monitoring. Its constant modernization provides the complete informational flow and reflects the innovative trends in the sustainable urban development.

The $3 d$ stage. It's a stage of diagnostics of the elements and instruments of monitoring operating in the megacity. It implies the actions in a framework of systematization of the requirements for monitoring. Here it is necessary to analyze the main significant components: accounting, control, planning and so on. The construction of the system of monitoring forms on the basis of results of the carried-out diagnostics (identified problems, requirements and limiting factors within the system of monitoring). 
The 4th stage. This stage is devoted to development an organizational model of monitoring. It consists of the methodological recommendations for determining the content, elements and principles of monitoring.

The most important principle of monitoring's functioning is the principle of a systematic approach. The use of a systematic approach predetermines the process of forming the monitoring system on the basis of functional, structural, organizational, elemental and methodical aspects.

The monitoring system involves the use of a new organizational and technical process, which is formed in real time and checked for efficiency as necessary. Obviously it is not possible to implement this idea in a framework of traditional linear-functional control system. So it will be better to use an object-functional management.

The structure of the organizational and technical process is formed depending on the time of its execution. It includes three subsystems:

1) Subsystem of the description of object;

2) Subsystem of the description of control of execution of organizational and technical actions;

3) Subsystem of analytical data processing.

For implementation of this organizational and technical process the functional communications and information streams are selected. They are superimposed on the hierarchical structure of management for controlling of various structure units and economic resources. The components of the hierarchical structure of management are defined by the composition of its constituent parts, elements, levels and the nature of their relationships. At the highest level, the goals for the entire management system are formalized. After that the functions and tasks of management, which can be detailed to individual organizational and technical processes are determined.

In order for the monitoring system to function properly, it is necessary to establish monitoring centers in each Department/Committee of the Administration of megacity. As a result the necessary management information could be obtained obtaining in real time.

The implementation of this proposal is related to the problem of the distribution of functions between the performers responsible for receiving, storing, transferring and using the information.

The monitoring center may have one or more responsibility centers for receiving and monitoring the information. In the process of designing the monitoring center, the rules of information transfer and the norms of control over the execution of individual stages are determined. The built network of monitoring centers should be dynamic and flexible for providing the development and adoption of all managerial decisions.

The monitoring centers should be technically connected with the analytical center. For this they include the blocks of input (information transfer) and output (information receiving) communication. At each stage of the monitoring process there are information resources that should be presented by information objects, their structure and content. Each information object reflects the real essence of investigated process. In this context there are three methods for description of these objects: temporal, numerical and symbolic. All others methods are derived from these methods.

It should be noted the important role of analytical function performing by the monitoring. Processing of the data array and presenting its results to the user is one of the main functions of the systems of operational analysis in the framework of monitoring the sustainable development of the megacity. In addition, the supporting the processing of information allows us to combine the methods of processing of each information object with group operations. It significantly increases the degree of flexibility of the entire data processing system. The proposed method allows us to use the unified modules in all monitoring centers. Such modules can be configured for input and output parameters, data 
transmission and control mechanisms on any of the selected responsibility centers. Unified module is included in the work of every responsibility center for providing the accuracy of organization-technical process. The result of the operation of this module should be an effective search for information in the data warehouse for the monitoring process functioning.

\section{Results}

The domestic and foreign practice shows us that a stable growth of economy is possible only in the conditions of building the integrated monitoring system. It is also true for the progress of financial performance, level of competitiveness, and sustainable urban development both in the national and in the global market. Conversely, the cause of slow rate of economic development, and even economic difficulties, is the lack of monitoring or its incompetence. Therefore, the organization of monitoring must correspond to the requirements of the scientific approach, reasonableness and balanceness of all processes [15]. It should provide an effective distribution of responsibilities and functions between individual performers and structural units of the Administration of the megacity.

However, the organization and conducting of monitoring is not limited to the fulfillment of the above requirements and conditions. In some cases it is necessary to distinguish clearly the objects and the subjects of monitoring. In this context it is necessary to create the interchangeable and complementary sectors within the framework of institutions engaged in analytical work. These are the sectors of investment, strategic, operational, tactical, personnel, financial and other types of monitoring. Today, as our analysis of Russian megacities shows, each separate Committee in the Administration, as a rule, conducts monitoring only for its own needs, without any correspondence with other executive authorities. Consequently the legislative bodies, today are practically deprived of the opportunity to receive the information they need to work, and have to use own separate information. At the same time, the monitoring should be carried out not only to analyze the current situation in the economy of the megacity, but also to find unused reserves (potential), as well as to develop the recommendations and methods for more detailed analysis. This is equally important for the modern business circles. So the entrepreneurs could make more effective management decisions on the basis of monitoring. It will allow them to timely bring the orders to performers and control their implementation [16].

Thus, the integration of all actions of various agents in the field of information support of development processes should become the basis for sustainable urban development of megacities.

\section{Discussion}

In these materials the author proposes to clarify the technology of working out the monitoring system at the level of the megacity. It should be designed in the form of a network including some monitoring centers. The starting point here is the definition of the organizational structure of the economy of the megacity and the current structure of the executive authorities. The monitoring system built on this basis plays the significant role in the organizational structure of management. Its functioning determines the level of access and the mode of working with information. It is also helps to set a criterion for evaluating the performance of each of the stages during the monitoring.

The center of responsibility for the information resources corresponds to each stage of the designed process. It forms the subsystem of the organizational structure of management for controlling the selected object of monitoring. In the process of designing, the rules of 
information transfer, the norms of control over the execution of individual stages and the specifics of all information flows are determined.

\section{Conclusions}

Thus, the proposed monitoring system will contribute to the development, adoption and implementation of managerial decisions aimed at sustainable innovative development of the megacities. At the same time, it creates the prerequisites for building a unified information environment for high-quality management of the economic system, not only in the megacities, but also regions and the country as a whole. This corresponds to the main trends of globalization, the Information society and postindustrial development of the socioeconomic system.

Use of the theoretical and methodical recommendations offered in this article will provide the solution of the General problem in a sphere of sustainable urban development.

\section{References}

1. T. L. Kharlamova, E. V. Fakhrutdinova, A. V Kharlamov, J. S. Kolesnikova. Globalization and its socio-economic consequences. 1 (17 th International Scientific Conference, Rajecke Teplice, 2017).

2. M. Galitskikh, Vedomosti, 2006.

3. http://www.pwc.ru/ru/technology/publications // The_New_Digital_Economy_june 2011.jhtml.

4. T. L. Kharlamova. Uch. zapiski RGGU. 19, 158 (2011).

5. K. Kostin K. AIMS. 9 (3), 183 (2015).

6. A. R. Bril, O. V. Kalinina, I. V. Ilin. Sustainable Economic Growth, Education Excellence, and Innovation Management through Vision 2020. (29 ${ }^{\text {th }}$ IBIMA Conference, 2017).

7. O. V. Kiselkina, A. V. Kharlamov, T. L. Kharlamova, A. F. Vunotropidi. Social Sciences and Interdisciplinary Behavior. 4th international congress ICIBSOS, 2016).

8. L. - M. Ang, K. P. Seng Big data research (Elsevier Inc., 4, 1, 2016).

9. A. S. Bhaskar, L. Beesley, M. J. Burns and others. Freshwater Sciences. 35 (1), 293 (2016).

10. T. L. Kharlamova, A.V. Kharlamov, O.S. Koroteeva. Vision 2020: Sustainable Economic development, Innovation Management, and Global Growth (30th IBIMA Conference, 2017).

11. T. L. Kharlamova. Higher Education International week. Saimaan ammattikorkeakoulun julkaisuja Sarja A: Raportteja ja tutkimuksia, 2017.

12. O. Aseeva. Izvestiya YZGU. Seriya: Ekonomika. Sotsiologiya. Menedzhment, 4 (21), 298 (2016).

13. G. G. Aralbaeva. Vestnik ekonom. integratsii, 5, 91(2008).

14. J. Kałkowska, A. V. Kozlov. Advances in Intelligent Systems and Computing, 431, 163 (2016).

15. B. S. Myrzaliev, L. T Taizhanov. Vestnik universiteta Turan, 1 (69), 227 (2016).

16. T. L. Kharlamova. Izvestiya SPbUEF, 4, 37 (2011). 